\title{
PRE-HOSPITAL ANALGESIA WITH ENTONOX
}

\author{
N. Donen, W.A. Tweed, D. White, B. Guttormson And J. Enns
}

\begin{abstract}
Pre-hospital self-administered analgesia using a 50:50 mixture of nitrous oxide and oxygen (Entonox) was evaluated in 240 patients. Of these, 93.4 per cent experienced either complete or partial relief from traumatic, chest, abdominal or back pain. Drowsiness was the most common side effect noted. No complications occurred during delivery of the mixture. Attention is drawn to the effect of extreme temperatures on the Entonox mixture and recommendations are made with respect to its use in below-freezing climates. Because of its ease of use and short duration of action, Entonox appears to be well suited for the treatment of pre-hospital pain by Emergency Medical Technicians.
\end{abstract}

KEY WORDS: ANALGESIA, casualty transport, Entonox.

UNTIL RECENTLY methods of providing prehospital analgesia have received little attention in the North American literature. In Britain, self-administered nitrous oxide in a 50:50 oxygen mixture (Entonox) has been enthusiastically accepted and promoted in the Ambulance Service for the past 10 years. Because of its ease of use, rapid onset and dissipation of action, and minimal side effects, Entonox was chosen for use in the City of Winnipeg Ambulance vehicles in February 1980. This paper will review our experiences with Entonox in the mangement of prehospital pain.

\section{Patients AND Methods}

Before the introduction of Entonox into use, an eight hour didactic and practical training program was conducted for the Emergency Medical Technicians by an anaesthetist and the Winnipeg Ambulance Service Training Department.

Entonox is supplied as a 50:50 gas mixture of nitrous oxide and oxygen. The delivery unit, attached to a pin index system, consists of a demand regulator and a light weight expiratory valve assembly which is attached to a transparent face mask. Thus the unit functions by using the

N. Donen, M.D.; W.A. Tweed, M.D.; D. White, B. Guttormson and J. Enns, from the departments of Medicine and Anesthesia, University of Manitoba, and the Winnipeg Ambulance Service.

Reprint requests to: N. Donen, M.D., Section Critical Care Services, St. Boniface General Hospital, 409 Tache Avenue, Winnipeg, Manitoba R2H 2 A6.

Can. Anaesth. Soc. J., vol. 29, no. 3, May 1982 demand or intermittent principle so that gas does not flow unless a negative pressure is applied to the inspiratory port. This, in essence, requires an air-tight seal between the mask and the face. Patients are instructed in the method of delivery and the Entonox is always self-administered by the patient.

A prospective study of the use of Entonox and its side effects was begun at the time of its introduction into the Winnipeg Ambulance Service. Two hundred and forty patients were studied. The indication to begin therapy was pain deemed severe enough by both the patient and the Emergency Medical Technician to require relief. The decision to start Entonox therapy was made by the technician at the scene, in accordance with the protocol listing the indications and contraindications for use (Table I). Evaluation included duration of administration, analgesic effect of the drug, ease of use, and side effects. Observations were tabled both by the patient and the technician.

One third of the patients were under 30 years of age, with a range of 5 to 98 years. Trauma accounted for 38 per cent of the administrations, while chest, abdominal and back pain accounted for another 46 per cent (Table II). Miscellaneous indications for use included labour pains, burns, headaches, gunshot wounds and leg pain.

\section{RESULTS}

\section{Duration of Use}

Duration of administration ranged between 5 275 and 10 minutes in 60 per cent of patients, and 98 
TABLE I

ENTONOX

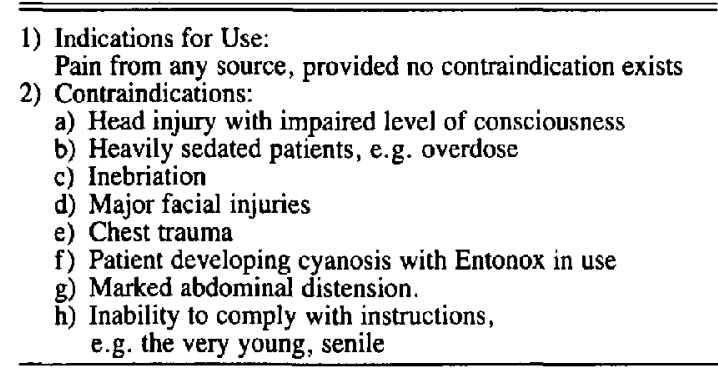

per cent of patients utilized the Entonox for less than 15 minutes.

\section{Pain Relief}

Results based on patient responses (Table III) indicate that 105 persons ( 44 per cent) obtained complete or marked relief of pain with selfadministration of the nitrous oxide/oxygen mixture. Another 119 patients (50 per cent) had partial relief of pain. Only seven of the 43 people experiencing abdominal pain obtained marked relief of pain $(\mathrm{p}<0.005$ by $\mathrm{Chi}$ squared analysis), although the majority described partial relief. No analgesia was reported by 16 persons ( 6.6 per cent) and they were evenly distributed amongst the five groups. Interpretation of pain relief by the technicians was similar; that for marked, partial or no relief of pain being 56,40 and 5 per cent respectively.

\section{Side Effects}

One hundred and sixty-four persons (68 per cent) noted side effects to the self-administration of Entonox (Table IV). Drowsiness was the most common side effect noted and occurred in 40 per cent of all persons using the drug. Forty-five patients (18.7 per cent) complained of either dizziness or vertigo. Nausea occurred in 12

TABLE II

ENTONOX - INDICATIONS FOR USE

\begin{tabular}{lr}
\hline \hline \multicolumn{1}{c}{ Indication } & $\begin{array}{c}\text { No. (\%) of } \\
\text { Patients }\end{array}$ \\
\hline Trauma & $92(38.3)$ \\
Chest pain & $45(18.8)$ \\
Abdominal pain & $43(17.9)$ \\
Back pain & $28(11.7)$ \\
Other & $32(13.3)$ \\
& 240(100) \\
\hline
\end{tabular}

patients ( 5 per cent) and another 10 listed such effects as numbness, headache or amnesia.

\section{Ease of Use and Decision to Utilize Entonox} Again

Only nine persons found the self-administration technique difficult. Eight individuals indicated that they would not use Entonox again. Seven of those eight had either obtained no relief from the Entonox or had complained of nausea. Thus 96.5 per cent of respondents found the technique easy to use and 96.8 per cent indicated they would use it again.

\section{Discussion}

The trend in Canada today is towards a more sophisticated emergency medical care system. The eventual goals are rapid stabilization at the scene, an advanced communication system with the hospital and the safe and efficient transfer of the victim to hospital. Pre-hospital analgesia is an important part of dealing with the accident victim or the person experiencing pain. The ideal analgesic would have no side effects, provide rapid relief of pain and have a short duration of action. It should neither cause cardiovascular or respiratory depression, nor mask a patient's symptoms and signs. Opiates are considered the mainstay of our analgesic therapy, but they are unsuitable in pre-hospital care of the trauma victim, as they can depress the level of consciousness, mask potential injuries, and their absorption and excretion in shock is unreliable.

Nitrous oxide has been used as an analgesic agent for almost 200 years. ${ }^{1}$ Non-operative therapeutic uses include pain relief in childbirth, from myocardial ischaemia, after acute trauma, and in the emergency department. ${ }^{2-6}$ Following a successful pilot study in Bristol, England in $1970,{ }^{7}$ Entonox was introduced into general use 
TABLE III

ANALgesic EfFect of Entonox

\begin{tabular}{|c|c|c|c|c|c|c|}
\hline \multirow[b]{3}{*}{ Group } & \multicolumn{6}{|c|}{ Analgesic Effect } \\
\hline & \multicolumn{2}{|c|}{ Marked } & \multicolumn{2}{|c|}{ Partial } & \multicolumn{2}{|c|}{ None } \\
\hline & $\mathbf{P}$ & $\mathrm{E}$ & $\mathbf{P}$ & $\mathbf{E}$ & $\mathbf{P}$ & $\mathrm{E}$ \\
\hline $\begin{array}{l}\text { Trauma } \\
\text { Chest Pain } \\
\text { Abdominal Pain } \\
\text { Back Pain } \\
\text { Miscellaneous }\end{array}$ & $\begin{array}{r}47 \\
19 \\
7 \\
16 \\
116\end{array}$ & $\begin{array}{l}59 \\
23 \\
16 \\
17 \\
19\end{array}$ & $\begin{array}{l}41 \\
21 \\
33 \\
10 \\
14\end{array}$ & $\begin{array}{r}31 \\
18 \\
25 \\
9 \\
12\end{array}$ & $\begin{array}{l}4 \\
5 \\
3 \\
2 \\
2\end{array}$ & $\begin{array}{l}2 \\
5 \\
2 \\
2 \\
1\end{array}$ \\
\hline $\begin{array}{l}\text { Total } \\
\%\end{array}$ & $\begin{array}{l}105 \\
43.8\end{array}$ & $\begin{array}{l}133 \\
55.8\end{array}$ & $\begin{array}{l}119 \\
49.6\end{array}$ & $\begin{array}{l}95 \\
39.6\end{array}$ & $\begin{array}{l}16 \\
6.6\end{array}$ & $\begin{array}{l}12 \\
4.6\end{array}$ \\
\hline
\end{tabular}

$P=$ patient response to analgesic effect.

$E=$ E.M.T. estimation of effect of Entonox analgesia.

TABLE IV

ENTONOX - SIDE EFFECTS

\begin{tabular}{ll}
\hline \hline & No. (\%) \\
\hline Drowsiness & $97(40.4)$ \\
Dizziness & $45(18.7)$ \\
Nausea & $12(5)$ \\
Other & $10(4)$ \\
\cline { 2 - 2 } & $164(68.1)$ \\
\hline
\end{tabular}

in the British Ambulance Service. ${ }^{8}$ Thal, ${ }^{9}$ Amey ${ }^{10}$ and McKinnon ${ }^{11}$ recently reported on similar studies in North America. All concluded that nitrous oxide analgesia was particularly well suited to the alleviation of pain in emergency conditions. They also felt that it served as an adjunct to the safe and improved emergency medical care of the pre-hospital patient.

Nitrous oxide is a colourless gas with a slightly sweet odour. It is a potent analgesic but a relatively weak anaesthetic agent, requiring concentrations of 60-70 per cent to produce unconsciousness. In combination with oxygen at concentrations between $35-50$ per cent it has been shown to have a rapid onset of action, effective analgesia, and minimal cardiovascular or respiratory depression. It is eliminated unchanged through the lungs within one to two minutes. ${ }^{12}$

Pre-mixed in equal proportions with oxygen in a cylinder, the net result is a single phase gas (Entonox) even when compressed to almost $13,780 \mathrm{kPa}(2000 \mathrm{lbs}$ per square inch) at temperatures above $-7^{\circ} \mathrm{C}$. Below $-7^{\circ} \mathrm{C}$ (the critical temperature of a 50:50 oxygen-nitrous oxide mixture) some of the ntirous oxide separates and settles as a liquid in the dependent portion of the cylinder. The net result is that initially an oxygen-rich gas is delivered, but as the tank empties an oxygen-poor mixture appears. $\mathrm{Re}_{-}$ warming the cylinders is not sufficient to reconstitute the single-phase mixture. Reconstitution of the gases to a single-phase requires both re-warming and agitation of the contents. The latter procedure usually involves inverting the cylinde $i$ a number of times after it has been warmed. ${ }^{13.14}$

Because of the extremes of the Winnipeg winter $\left(-20\right.$ to $\left.-40^{\circ} \mathrm{C}\right)$ special precautions were taken to prevent this gas separation. All cylinders were positioned horizontally in the ambulance vehicles, since reversion in the absence of agitation to a single gas phase takes place more rapidly with the cylinder in the horizontal rather than in the vertical position. ${ }^{15}$ While involved in patient transport the vehicle engines were kept running even when stationary while away from the ambulance stations. When not in use the vehicles were kept in their stations. In this way the temperatures in the ambulances were kept at $10^{\circ} \mathrm{C}$ or greater. At the beginning of each shift, or when the cylinders had been exposed to temperature below $10^{\circ} \mathrm{C}$, they were inverted a number of times. At no stage were any of the cylinders in use exposed to temperatures below freezing for longer than 10 minutes. This point is worth stressing, particularly because of the extremes of the Manitoba winter. If nitrous oxide-oxygen analgesia is planned in areas of extreme temperatures and the tanks are to be exposed to the cold for any period of time, then it would be advisable to use a different delivery system, such as the Nitronox ${ }^{3}$. This portable delivery system consists of a two-tank unit, one for the nitrous oxide, the other oxygen. Gas is drawn from each tank and mixed in 50:50 
proportions. The apparent advantage of this system is that it has a fail safe valve which automatically shuts off nitrous oxide delivery when the oxygen supply becomes depleted.

Because nitrous oxide is 34 times more soluble than nitrogen, delivery of this gas will result in an increase in volume of any gascontaining cavity in the body. Eger and Saidman $^{16}$ have shown an exponential rise in the gas pocket volume depending on the concentration of nitrous oxide used. Fifty per cent nitrous oxide will cause a 100 per cent increase, while $70-80$ per cent nitrous oxide delivery results in a 400 per cent increase in volume. They also showed that when delivering 70 per cent nitrous oxide continuously, the intestinal volume will double after two hours, but the lung volume, e.g. from a pneumothorax, doubles after 10 minutes. For these reasons delivery of Entonox is contraindicated in patients with a markedly distended abdomen or chest trauma where a pneumothorax might have resulted.

Entonox was extremely well accepted by the patients and the technicians. We have been impressed by the efficacy of Entonox in the wide range of pain syndromes presented. The incidence of 6.6 per cent of patients who obtained no relief with the Entonox is in keeping with other studies. ${ }^{6,8-10}$ All others experienced either partial or complete pain relief. It was of interest to note the low number of patients who obtained complete relief when complaining of abdominal pain. The reason for this is not clear and is being studied further. However, in assessing pain relief one must realize that assessment is necessarily subjective and placebo effects must be acknowledged. We considered it unethical to include a placebo in this study.

As expected and in keeping with its action, drowsiness was the most common side effect noted. No patients were unconscious at any stage. Nausea appears to have been the most undesirable of the side effects. Ten of the twelve patients who developed nausea did, however, indicate that they would use the drug again. Although in asymptomatic patients with coronary artery disease, 50 per cent nitrous oxide may depress cardiac contractility, cardiac output and raise left ventricular end diastolic pressures, ${ }^{17} \mathrm{Kerr}^{18}$ showed that in the presence of ischaemic cardiac pain these parameters remained stable when the patients were given Entonox. No marked alterations of pulse, blood pressure or skin colour were noted in our patients. Because of the self-administration of the drug, we believe it is extremely difficult to induce major adverse effects provided the guidelines for indications and contraindications are closely adhered to.

Fink $^{19}$ in 1955 drew attention to the possibility of developing hypoxaemia immediately after the use of nitrous oxide. Studies by Roesch ${ }^{20}$ and Sheffer ${ }^{21}$ using 21 per cent oxygen and 79 per cent nitrous oxide showed a mean maximal drop in $\mathrm{Pa}_{\mathrm{O}_{2}}$ of 15 torr $2 \frac{1}{2}$ minutes after the nitrous oxide had been discontinued. Baskett, ${ }^{22}$ analyzing six spontaneously breathing patients, showed that $\mathrm{Pa}_{\mathrm{O}_{2}}$ values were at least doubled from room air samples when Entonox was administered. Although we did not study this effect on our patients we assumed, based on Baskett's work, that even though the $\mathrm{Pa}_{\mathrm{O}_{2}}$ might fall somewhat after discontinuation of the Entonox, this drop will not be as low as $\mathrm{Pa}_{\mathrm{O}_{2}}$ on room air.

Contamination within the closed vehicle atmosphere has not been considered a problem. Each ambulance is equipped with a motor driven exhaust fan. Analyzing various sections of an ambulance Ancker ${ }^{23}$ obtained nitrous oxide levels between 650 and 1700 p.p.m. (maximum 7500 p.p.m.) in the breathing zone of the attendant at the side of a patient using Entonox when the exhaust system was not in operation. With the exhaust fan in use the concentration of nitrous oxide fell to less than 50 p.p.m.

On the basis of this study, Entonox appears to be a safe analgesic and well suited for the treatment of pre-hospital pain by Emergency Medical Technicians, provided that due care is taken with respect to indications and contraindications, and that there is a clear understanding of the effects of extreme temperatures on the Entonox delivery system.

\section{ACKNOWLEDGEMENTS}

The assistance of the personnel and Emergency Medical Technicians of the Winnipeg Ambulance Service, Mr. J. McKinley and Mrs. Donna Eastoe, in the preparation of the studies are generously acknowledged.

\section{REFERENCES}

1. DAvY, H. Researches, chemical and philosophical; Chiefly concerning nitrous oxide or dephlogisticated nitrous air and its respiration. London: J. Johnson (1800).

2. Parbrook, G.D.P. Therapeutic uses of nitrous oxide. Brit. J. Anaesth. 40: 365 (1968). 
3. Hustead, R.F. Nitrous oxide in obstetrics. Clin. Anesth. 1: 98 (1964).

4. KerR, F., Hoskins, M.R., Brown, M.G., EWING, D.J., IRving, J.B. \& KIRBY, B.J. A double-blind trial of patient controlled nitrous oxide/oxygen analgesia in myocardial infarction. Lancet 1: 1397, (1975).

5. BasketT, P.J.F. \& BenNetT, J.A. Pain relief in hospital: the more widespread use of nitrous oxide. Brit. Med. J. 2: 509 (1971).

6. McKinnon, K.D.L, Culver, D. \& Prno, J.M. Nitrous oxide/oxygen analgesia in emergency care. Can. Fam. Physician 26: 83 (1980).

7. Baskett, P.J.F. \& Withnell, A. The use of Entonox in the Ambulance Service. Brit. Med. J. 2: $41(1970)$.

8. Wrught, C.J., McDowall, D.G., Wilson, J., HAIN, W.R., FurNess, R. \& DAYKIN, J.H. Pre-mixed ntirous oxide-oxygen analgesia in the ambulance service. Anaesthesia 27: 459 (1972).

9. Thal, E.R., Montgomery, S.J., Atkins, J.M. \& RoberTs, B.G. Self administered analgesia with nitrous oxide. J.A.M.A. 242: 2418 (1979).

10. AmeY, B.D., Ballinger, J.A. \& Harrison, E.E. Pre-hospital adminstration of nitrous oxide for control of pain. Ann. Emerg. Med. 10:247 (1981).

11. McKinnon, K.D.L. Pre-hospital analgesia with nitrous oxide/oxygen. C.M.A.J. I25: 836 (1981).

12. Latro, I.P., Molloy, M.J. \& Rosen, M. Arterial concentrations of nitrous oxide during intermittent patient controlled inhalation of $50 \%$ nitrous oxide in oxygen (Entonox) during the first stage of labour. Brit. J. Anesth. 45: 1029 (1973).

13. TUNSTALL, M.E. Implications of pre-mixed gases and apparatus for their administration. Brit. J. Anaesth. 40: 675 (1968).
14. Selwyn Crawford, J., Ellis, D.B., Hill, D.W. \& PAYNE, J.P. Effects of cooling on the safety of pre-mixed gases. Brit. Med. J. 2: 138 (1967).

15. Bracken, A., Broughton, G.B. \& Hill, D.W. Safety precautions to be observed with cooled pre-mixed gases. Brit. Med. J. 3: 715 (1968).

16. Eger, E.I. \& SAlDMAN, L.J. Hazards of $\mathrm{N}_{2} \mathrm{O}$ anesthesia in bowel obstruction and pneumothorax. Anesthesiology 26: 61 (1965).

17. Eisele, J.H., Reitan, J.A., Massumi, R.A., ZELLIS, R.F \& MiLler, R.D. Myocardial performance and $\mathrm{N}_{2} \mathrm{O}$ analgesia in coronary artery disease. Anesthesiology 44: 16 (1976).

18. KERR, F., EWING, D.J., Irving, J.B. \& KIRBY, B.J. Nitrous oxide analgesia in myocardial infarction. Lancet 1: 63 (1972).

19. Fink, B.R. Diffusion anoxia. Anesthesiology 16: $511(1955)$.

20. Roesch, R. \& Stoelting, R. Duration of hypoxemia during nitrous oxide excretion. Anesth. and Anal. 51: 851 (1972).

21. Sheffer, L., Steffenson, J.L. \& Birch, A.A. Nitrous oxide induced diffusion hypoxia in patients breathing spontaneously. Anesthesiology 37: 436 (1972).

22. Baskett, P.J.F., Eltringham, R.J. \& BenNETT, J.A. An assessment of the oxygen tensions obtained with pre-mixed $50 \%$ nitrous oxide and oxygen mixture (Entonox) used for pain relief. 5 th World Congress of Anesthesiologists, Kyoto, Japan (1972)

23. ANCKeR, K., Halldin, M. \& Gothe, C.J. Nitrous oxide analgesia during ambulance transportation. Airborne levels of nitrous oxide. Acta Anaesth. Scand. 24: 497 (1980).

\section{REsumE}

L'analgésie procurée par un mélange égal de protoxyde d'azote et d'oxygène (Entonox) a été évaluée en auto-administration sur 240 patients. Parmi ceux-ci, 93.4 pour cent ont été complètement ou partiellement soulagés d'une douleur d'origine traumatique située au thorax, à l'abdomen ou au dos. La somnolence a été l'effet secondaire le plus fréquent. Il n'y a eu aucune complication lors de l'administration du mélange. Les effets des températures excessives sur le mélagne Entonox sont décrits et des recommandations pour son utilisation dans les climats où la température descend sous le point de congélation. Etant donné sa grande facilité d'emploi et sa courte durée d'action, l'Entonox nous semble un bon analgésique qui a l'avantage de pouvoir être utilisé par des paramédicaux à la période qui précède l'hospitalisation. 